\title{
Human Cytotrophoblastic Antigens Defined by Monoclonal Antibodies
}

\author{
Yuya Abe, Kunihiro Okamura, Yoichi Hamazaki, \\ Yuichi Wada and Akira Yajima \\ Department of Obstetrics and Gynecology, Tohoku \\ University School of Medicine, Sendai 980
}

\begin{abstract}
Abe, Y., Okamura, K., Hamazaki, Y., Wada, Y. and Yajima, A. Human Cytotrophoblastic Antigens Defined by Monoclonal Antibodies. Tohoku J. exp. Med., 1988, 154 (3), 245-251 Monoclonal antibodies have been raised against cytotrophoblast. Two different antigens, defined on cytotrophoblast but not on syncytiotrophoblast were designated ACT-1 and ACT-2, respectively. Chorionic villi were taken from normal early pregnancy and processed for immunization by two different procedures. ACT-1 was demonstrated to be present in lung alveolar cells, endothelial mucosa of the jejunum, colon, ureter, urinary bladder and the fallopian tube, and endometrial gland of the pregnant uterus. On the other hand, ACT-2 was present in the endothelial mucosa of the stomach, endothelium of the renal vessel, and the decidua of the pregnant uterus. Although the monoclonal antibodies did not react with such established cell lines as Bewo, SCH, OVK-18, HHUA, MK-01, FL, BHK and P3 $\times 63 \mathrm{Ag} 8.653$, they did react with some of the cell lines when the cell membrane was destroyed with Triton X-100. Each antibody, therefore, may recognize the antigen not on the cell membrane but in the cytoplasm. The atigens might be shed or may disappear in the process of differentiation from cytotrophoblast to syncytiotrophoblast. —— monoclonal antibody ; cytotrophoblast
\end{abstract}

Trophoblast exist at the interface between mother and fetus which may be considered a semi-allograft. It should function as an immunoprotective barrier in favor of the fetus. Trophoblasts are morphologically classified into syncytiotrophoblasts in the outer layer of villi and cytotrophoblasts in the inner layer. The syncytiotrophoblast is a multinucleated cell so that it is considered to be differentiated from cell fusion of cytotrophoblasts (Pierce and Midgly 1963). It is a very important point in examining character and function of the cytotrophoblast that antigenicity in the cytotrophoblast may be modulated or shed in the process of fetal growth. We have succeeded in raising two monoclonal antibodies, each of which has high affinity with the cytotrophoblast, but not with the syncytiotrophoblast.

Received December 23, 1987 ; revision accepted for publication February 9, 1988. 


\section{Materials and Methods}

\section{Immunizing source was prepared by two methods}

Method 1. Normal chorionic villi of six to nine weeks of gestation were obtained by D \& C. After washing with phosphate buffered saline (PBS) to remove as much blood as possible, villi were minced with scissors and digested in an enzyme solution containing $0.2 \%$ trypsin (Gibco, Grand Island, NY, USA), $120 \mu / \mathrm{ml}$ collagenase (Wako, Osaka) and $60 \mu / \mathrm{ml}$ DNAase (Sigma, St. Louis, MO, USA) in $10 \mathrm{ml}$ of PBS in $1 \mathrm{~g}$ of wet tissue. The tissue solution was gently stirred at $37^{\circ} \mathrm{C}$. Half the supernatant was taken every $15 \mathrm{~min}$, adding the same volume of the fresh enzyme solution each time. After $60 \mathrm{~min}$, the digestion was stopped by adding 10\% fetal calf serum (FCS). After passing through stainless mesh ( \#200), the cell suspension was washed with PBS three times and overlayered Ficoll-Conray solution $(p=1.082)$ and centrifuged at $400 \mathrm{~g}$ to remove red blood corpuscle. The cell suspension was then centrifuged at $400 \mathrm{~g}$ for $20 \mathrm{~min}$ in discontious Percoll gradient solution in which the gradient varied from 1.060 to 1.075. The layer between 1.066 and 1.075 enriched in cytotrophoblasts (Wilson et al. 1983) was collected with a fine pipett and washed with PBS three times. Three to four million cells were injected into the peritoneal cavity of a BALB/C mouse for immunization.

Method 2. Microvilli were collected by the simple saline extraction technique originally reported by Smith et al. 1974. In brief, normal chorion at 6-9 weeks of gestation was taken by $\mathrm{D} \& \mathrm{C}$ and washed with isotonic $\mathrm{CaCl}_{2}$ solution. After removing the blood, the chorion was gently stirred in ice-cold saline for $30 \mathrm{~min}$. The supernatant was centrifuged at $800 \mathrm{~g}$ for $10 \mathrm{~min}$ to remove debris and then was centrifuged at $10,000 \mathrm{~g}$ for $5 \mathrm{~min}$. The supernatant was subsequently centrifuged at $100,000 \mathrm{~g}$ for $60 \mathrm{~min}$ to obtain a microvilli pellet. A pellet 25 to $30 \mathrm{mg}$ wet weight was injected into a mouse for immunization.

\section{Production of monoclonal antibodies}

$\mathrm{BALB} / \mathrm{C}$ male mice were immunized and boosted three to four times every 2 weeks with each antigen source by intraperitoneal injection. Three days after the last boost, spleen cells were harvested and fused to $\mathrm{P} 3 \times 63 \mathrm{Ag} 8.653$ myeloma cells in the presence of $50 \%$ polyethylene glycol 1500 (Boehringer Mannheim, Mannheim, FRG) or 1540 (Wako). After fusion, the cells were dispensed and incubated in 96 well plates in $1 \mu \mathrm{M}$ hypoxanthine/ $0.4 \mu \mathrm{M}$ aminopterin $/ 16 \mu \mathrm{M}$ thymidine $/ 15 \%$ FCS.

\section{Initial screening of hybridoma production and cloning}

On the 14th day after fusion, culture suprenates were harvested and screened for antibodies by immunoperoxidase staining to normal early pregnancy chorion. Individual viable cells from positive culture wells were cloned by limiting dilution. The desired monoclonal antibodies were obtained from the supernates of the hybridoma or the ascites of $\mathrm{BALB} / \mathrm{C}$ mice inoculated with the hybridoma. Monoclonal antibody isotypes were determined by reaction with mouse allotype-specific immunoglobulin-labeled monclonal antibodies.

Normal early chorion with M-1 embedding matrix.(Lipshow, Detroit, MI, USA) was quickly frozen in liquid nitrogen and sectioned at $6 \mu \mathrm{m}$ by cryostat. Dried and fixed with aceton for $10 \mathrm{~min}$, the sectioned material was reacted with normal horse serum (Vector) for $10 \mathrm{~min}$ to block nonspecific reactions. After washing three time with PBS, the embedded chorion was reacted with the monoclonal antibody for $12 \mathrm{hr}$ at $4^{\circ} \mathrm{C}$.

Immunoperoxidase staining was then carried out as usual as a serial reaction of biotinylated antibody to mouse IgG (Vector), avidin DH biotinylated horseraddish peroxydase complex and $0.02 \%$ diaminobenzidin $\mathrm{H}_{2} \mathrm{O}_{2}$ as a substrate. Methylgreen staining was used for nucleus staining. 


\section{Enzymic treatment}

To investigate the enzyme sensitivty of the antigenic determinants recongnized by the monoclonal antibodies, freezed dried specimens on slide glass were incubated at $37^{\circ} \mathrm{C}$ for an hour in the presence of various enzymes and then washed and processed for immunoperoxidase staining. Enzymes used were pepsin (Sigma), actinase E (Kaken, Tokyo), trypsin (Difco, Detroit, MI, USA), dispase (Godoshusei), hyaluronidase (Sigma) and neuraminidase (Sigma). In addition to the enzymic treatment, we examined sensitivity to $\mathrm{NaIO}_{4}$, heat stability and fragility when embedded in parafin.

Staining to established cell lines

Cell lines used were Bewo (choriocarcinoma), SCH (gastric choriocarcinoma), OVK-18 (ovarian endometrioid carcinoma), HHUA (endometrial carcinoma), MK-01 (gastric cancer), P3 $\times 63 \mathrm{Ag}$ 8.653 (mouse myeloma), FL (human amniotic cell) and BHK (hamster kidney).

Staining to normal tissue

Normal lung, stomach, jejunum, colon, kidney, ureter, urine bladder, spleen liver and fallopian tube tissue were obtained from portions of surgical specimens not required for pathologic examination. Endometrium from 10 weeks of gestation was obtained at D \& C. Tissue was froze, cut and stained as described.

\section{Results}

. According to method 1 in which $1.2 \times 10^{8}$ splenocytes were fused with $2.5 \times$ $10^{7}$, myeloma cells, hybridoma grew in 217 of 360 wells $(60.3 \%)$ and production of antibodies to the trophoblasts was observed in 37 wells $(10.3 \%)$. However, there was only one antibody which did not react with syncytiotrophoblast but did with cytotrophoblasts. The antigen defined by the antibody was designated ACT-1. A subclass of immunoglobulin of anti-ACT-1 antibody was IgM. In

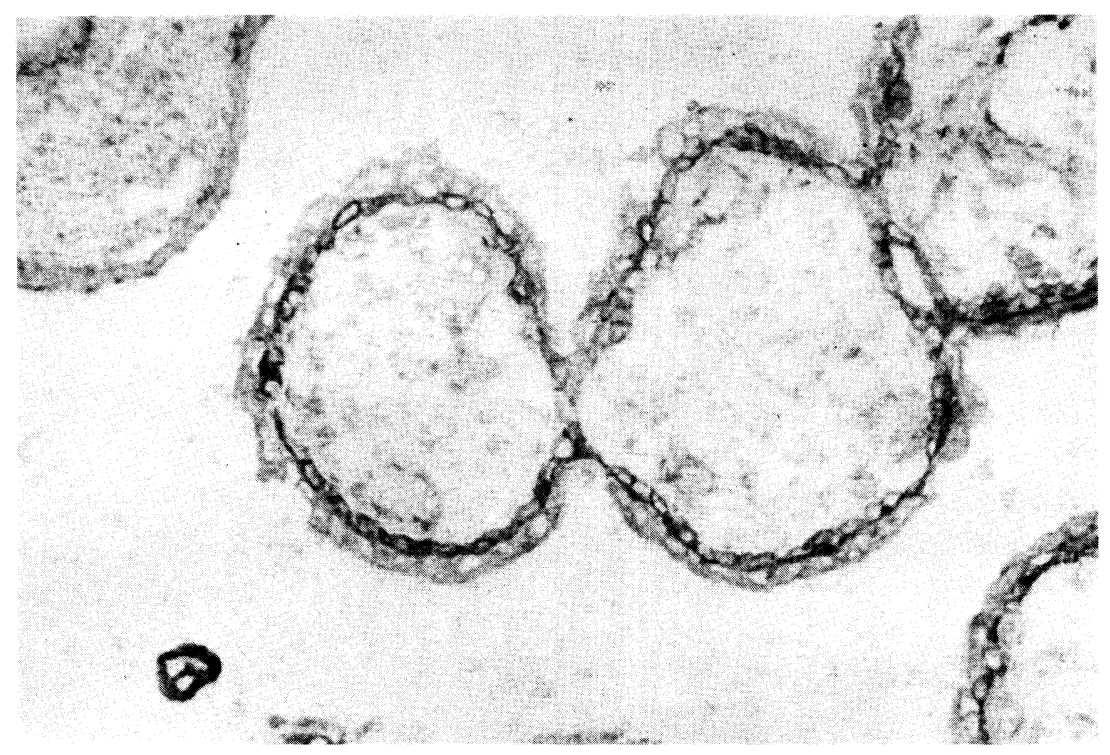

Fig. 1. Localization of ACT-1 in the villi. $(\times 100)$ 


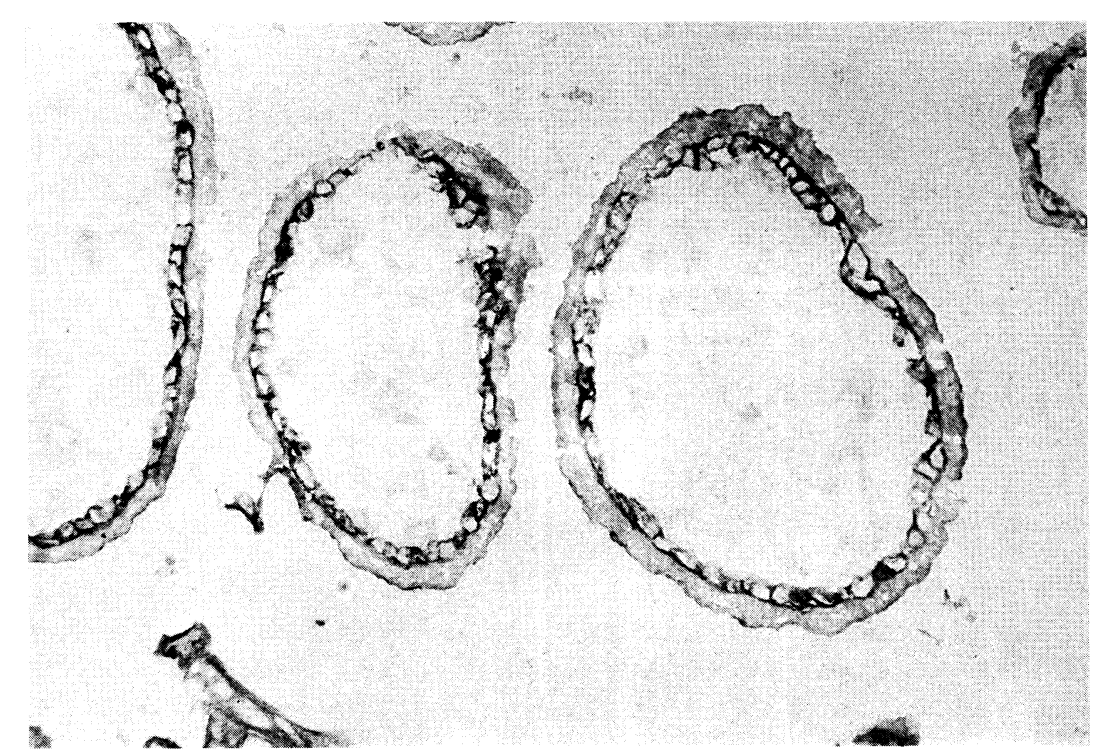

Fig. 2. Localization of ACT-2 in the villi. $(\times 100)$

method 2, $2.0 \times 10^{8}$ splenocytes were fused with $2.7 \times 10^{7}$ myeloma cells. Hybridoma grew in 133 of 300 wells and production of antibody was observed in 118 wells $(39.3 \%)$. Of the antibodies, only one reacted with cytotrophoblasts. not with syncytiotrophoblasts, the immunoglobulin of which was IgGl. The antigen

TABle 1. Localization of $A C T-1$ and $A C T-2$ in normal organs

\begin{tabular}{lcc}
\hline & ACT-1 & ACT-2 \\
\hline Lung & Alveolar cell & $(-)$ \\
Stomach & $(-)$ & $\begin{array}{c}\text { Basement membrane } \\
\text { of mucosa }\end{array}$ \\
Jejunum & Mucosal epithelium & $(-)$ \\
Colon & Mucosal epithelium & $(-)$ \\
Kidney & $(-)$ & Mucosal epithelium \\
Ureter & Mucosal epithelium & $(-)$ \\
Urine bladder & Mucosal epithelium & $(-)$ \\
Spleen & $(-)$ & $(-)$ \\
Liver & $(-)$ & $(-)$ \\
Fallopian tube & Mucosal epithelium & $(-)$ \\
Endometrium & & Epithelial cell \\
10 weeks gestation & Part of epithelial cell & Decidual cell \\
Endometrial gland & $(-)$ & $(-)$ \\
Decidua & $(-)$ & Secretory phase
\end{tabular}


TABLE 2. Localization of $A C T-1$ and $A C T-2$ in various established cell lines and the change of antigenicity by the treatment of Triton X-100

\begin{tabular}{lcccc}
\hline \multirow{2}{*}{ Treated with Triton } & \multicolumn{2}{c}{ ACT-1 } & \multicolumn{2}{c}{ ACT-2 } \\
\cline { 2 - 5 } & $(-)$ & $(+)$ & $(-)$ & $(+)$ \\
\hline Bewo & - & - & - & + \\
SCH & - & + & - & + \\
OVK-18 & - & - & - & + \\
HHUA & N.D. & + & - & + \\
MK-01 & - & - & + & + \\
p3 $\times 63$ Ag8.653 & - & - & - & - \\
FL & - & - & - & - \\
BHK & - & - & - & + \\
\hline
\end{tabular}

N.D., not done.

defined by the antibody was designated ACT-2. ACT-1 was present in cytotrophoblasts but not in syncytiotrophoblasts, although the antigen was faintly recognized in interstitial tissues (Fig. 1). ACT-2 was more specific to cytotrophoblasts than was ACT-1 (Fig. 2). The presence of the antigens in other normal tissues is shown in Table 1. ACT-1 was also present in alveolar cells of lung, epithelial mucosa of jejunum, colon, ureter, urine bladder and fallopian tube and the endometrial gland of pregnant uterus and was not present in the epithelial mucosa of the stomach and kidney or decidua, whereas ACT-2 was present in epithelial mucosa of the stomach, kidney, endometrium of prenant uterus and decidua cells. Reactivity of the two antibodies to various established cell lines is shown in Table 1. No cell lines other than MK-01 were stained by either anti-ACT-1 or -2 , but some became stainable using the antibodies after treatment with Triton X-100.

TABLE 3. Changes of antigenicity of ACT-1 and ACT-2 by the treatment of Triton X-100

\begin{tabular}{lcc}
\hline & ACT-1 & ACT-2 \\
\hline Pepsin, $10 \mu / \mathrm{ml}, 37^{\circ} \mathrm{C}, 1 \mathrm{hr}$ & $\mathrm{S}$ & $\mathrm{S}$ \\
Actinase $\mathrm{E}, 5 \mu \mathrm{g} / \mathrm{ml}, 37^{\circ} \mathrm{C}, 1 \mathrm{hr}$ & $\mathrm{S}$ & $\mathrm{S}$ \\
Trypsin, $50 \mu \mathrm{g} / \mathrm{ml}, 37^{\circ} \mathrm{C}, 1 \mathrm{hr}$ & $\mathrm{R}$ & $\mathrm{R}$ \\
Dispase, $10 \mathrm{U} / \mathrm{ml}, 37^{\circ} \mathrm{C}, 1 \mathrm{hr}$ & $\mathrm{R}$ & $\mathrm{R}$ \\
Hyaluronidase, $100 \mathrm{U} / \mathrm{ml}, 37^{\circ} \mathrm{C}, 1 \mathrm{hr}$ & $\mathrm{R}$ & $\mathrm{R}$ \\
Neuraminidase, $0.1 \mathrm{U} / \mathrm{ml}, 37^{\circ} \mathrm{C}, 1 \mathrm{hr}$ & $\mathrm{R}$ & $\mathrm{R}$ \\
NaIO $_{4} 5 \mathrm{mM}, 4^{\circ} \mathrm{C}, 1 \mathrm{hr}$ & $\mathrm{R}$ & $\mathrm{R}$ \\
${\text { Heat, } 100^{\circ} \mathrm{C}, 10 \mathrm{~min}}_{\text {Paraffin embedded }}$ & $\mathrm{S}$ & $\mathrm{S}$ \\
\hline
\end{tabular}

$\mathrm{S}$, sensitive; R, resistant. 
The antigen determinant of ACT-1 was heatlabile and sensitive to pepsin. That of ACT-2 was heatlabile, sensitive to pepsin and also destroyed in the process of paraffin embedding (Table 3 ).

\section{Discussion}

We have reported the production of monoclonal antibodies raised against the cytotrophoblast. Two newly recognized antigens designated ACT-1 and ACT-2 have been defined with these monoclonal antibodies. The character of these antigens should be protein because they were heatlabile and destroyed by enzymic treatment. In some established cell lines, these antigens were stained by the immunoperoxidase method after treatment with Triton X-100. Therefore these antigens, specially ACT-2, should be present on the cytoplasmic site of such cells as Bewo, SCH, OVK-18, HHUA and BHK.

Considering the distribution of the two antigens in normal tissue and established cells lines, these antigens must differ in character from each other. We do not say that the two antigens were "cytotrophoblast specific", considering the fact that these antigens were present in normal tissue. However, since it is generally accepted that cytotrophoblast given rise to the sycytium by fusion of mature cytotrophoblast cells resulting in the multinucleate tissue characteristic of the syncytiotrophoblast (Carter 1964 ; Enders 1965), we think that these antigens, ACT-1, and -2, may be shed or may disappear in the process of differentiation from cytotrophoblast to syncytiotrophoblast. The function of these antigens fulfilled in cytotrophoblast and normal tissues is currently unknown. In this regard, this modulation or disappearance of the antigens in the syncytiotrophoblast is very interesting because the syncytiotrophoblast, located at the outher surface of the placenta and possibly exposed to immunological attack from maternal lymphocytes, may be immunologically inert. There have been some reports (Loke and Day 1984 ; Contractor and Sooranna 1986; Yamashita et al. 1986) that monoclonal antibody was raised against cytotrophoblast. There may be several more antigens present on the cytotrophoblast but absent on the syncytiotrophoblast, although not many. Further study will be required to identify and analyse the similarities of such cytotrophoblastic antigens, including ACT-1 and ACT-2.

\section{References}

1) Carter, J.E. (1964) Morphological evidence of syncytial formation from the cytotrophoblast. Obstet. Gynec., 23, 647-656.

2) Contractor, S.F. \& Sooranna, S.R. (1986) Monoclonal antibodies to cytotrophoblast and syncytiotrophoblast of human placenta. J. develop. Physiol., 8, 277-282.

3) Enders, A.C. (1965) A comparative study of the fine structure of the trophoblast in several haemochorial placentae. Amer. J. Anat., 116, 29-67.

4) Loke, Y.W. \& Day, S. (1984) Monoclonal antibody to human cytotrophoblast. Amer. J. reprod. Immunol., 5, 106-108.

5) Pierce, G.B., Jr. \& Midgly, A.R., Jr. (1963) Origin and function of human sycytium 
giant cells. Amer. J. Path., 43, 153-173.

6) Smith, N.C., Brush, M.G. \& Luckett, S. (1974) Preparation of human placental villous surface membrane. Nature (Lond.), 252, 302-303.

7) Wilson, C.B., Haas, J.E. \& Weaver, W.M. (1983) Isolation, purification, and characteristics of mononuclear phagocytes from human placenta. J. immunol. Meth., 56, 305-317.

8) Yamashita, K., Nakamura, T., Shimizu, T. \& Ohno, H. (1986) Monoclonal antibodies to human choriocarcinoma. Amer. J. reprod. Immunol. Microbiol., 11, 130-134. 